Editorial

Journal of Dental Science, Oral \& Maxillofacial Research

\title{
We are proud to launch first inaugural issue of the new peer-reviewed
}

\section{Diyar Kh. Bakr}

Ph.D (Conservative), Lecturer, Head of Higher Education Unite / HMU / College of Dentistry, Iraq

Correspondence: Diyar Kh. Bakr, Ph.D (Conservative), lecturer, Head of Higher Education Unite / HMU / College of Dentistry, Tel: +00964 750472 0452, Iraq, Email divya.bakr@den.hmu.edu.iq

Received: September 19, 2017 | Published: October 04, 2017

Copyright@ 2017 Hambartsoumian et al. This is an open access article distributed under the terms of the Creative Commons Attribution License, which permits unrestricted use, distribution, and reproduction in any medium, provided the original author and source are credited.

\section{Introduction}

We are proud to launch first inaugural issue of the new peer-reviewed high quality Journal under the name of Dental Science, Oral and Maxillofacial Research to the national and internatioanl dentsists and oral science researchers .

It is a great honor to introduce myself as associated editor of the Journal, I am excited about the future of the journal and my ambition is to look forward to continuing to work together to make this new Journal a perfect journal and I hope you will agree that this inaugural Our aim is to make the Journal an open access journal that will satisfactory accommodate research manuscripts from the world wide of dentistry as we strongly believe that always knowledge must be free.

Finally it's my pleasure to invite everyone to be a part of JDSOMR by becoming a permanent reader or writer and contributing original article in your sphere to future issues. 